\title{
E-Agriculture Information Monitoring System using Data Mining
}

\author{
Dhakne Aniket ${ }^{1}$, Deshpande Mayur ${ }^{2}$, Patharkar Mayur ${ }^{3}$, Rathod Aakash ${ }^{4}$ \\ Students, Department of Computer Engineering, Dr. D. Y. Patil Institute of Technology, Pimpri, Savitribai Phule Pune \\ University, Pune, India ${ }^{1,2,3,4}$
}

\begin{abstract}
Agriculture is one of the important sector in India. Most of the Indian population is engaged in agriculture occupation. Most of the Indian farmers do farming in traditional way they are unaware of new technologies and trends in market. Farmers work hard for growing good quality of crop. Indian farmers also have to face adverse climatically effects. After this when farmer sells there agriculture produce in market they are cheated by the market traders and commission agents. All these factors lead to making Indian farming community economically infirm. Information and communication technology (ICT) can play important role in agriculture sector to increase income and economical standard of farmer. Agriculture is very information intensive industry but information related to this sector is not properly maintained. The advantages of ICT will be very helpful for providing accurate and timely relevant information about weather and market prices to farmers this will be helpful for facilitating an environment for remunerative agriculture. In this paper we are interested to introduce a new web portal system based on agriculture market which will be helpful for farmers and market traders to sell and buy agriculture products easily and efficiently. Our system intends to provide reliable and efficient communication and interaction platform between different stakeholders of market like farmers, traders and government officials. System will provide timely updates about weather information, market prices and minimum support prices of different crops. System focuses on making use of advantages of ICT to bring transparency and accuracy in Agriculture Produce Market Committee (APMC) and making Indian farmers ready to compete with farmers of developed countries in globalised market.
\end{abstract}

Keywords: Data mining, K- means, Apriori algorithm, k-NN Algorithm, Weather API, APMC, E-Agriculture.

\section{INTRODUCTION}

Agriculture sector is critically important for developing country like India, because of agricultural contribution in GDP and human resources engaged with this sector. Agriculture is an information intensive industry which is spatial in nature. Information and communication technology can play very important role for managing and accessing this information and make use of available records efficiently. ICT can help to provide helpful and necessary information to farmers and keep them aware of new market trends. According to National Sample Survey Organizations $59^{\text {th }}$ round survey, the information about fertilizers and seeds was most frequently accessed, and information about different market prices of agriculture commodities was second most important information accessed by farmers. ICT plays an important role in agriculture marketing by properly and timely record keeping. ICT will also helpful for detailed cost analysis and find out most sophisticated market strategies. Trade in Indian agriculture market (APMC) market are carried as direct auction by licensed commission agent, and details are manually noted by commission agent, because of this government does not have on time and accurate trade records.

E-Agriculture system is our attempt to enforce e-governance on agriculture market. System will have different registration and log-in for different stakeholders like farmer, trader and government. System will provide an access to government for all the market details of transactions. Government will have access to all the database records of farmers, merchants and market transactions. Farmer can add the crop details and quantity to their cart for selling purpose, similar way merchant will also add crop names and respective purchasing prices for crops to buy. Farmer and merchant will be able to see the minimum support prices of different crops defined by government. This will help government to assure that farmer will get fair price for his product. Farmer will be able to find the nearest APMC merchants who are offering highest price to his crops. Similar way merchant can also find nearest location farmers with required crops for buying purpose. Government will be able to see all transactions between merchant and farmer it can see how much product is sold and for what price it is sold. Government will keep all track of details for analysis purpose which will be helpful for future decision and policy making.

System generates unique ID for farmers and government licensed merchant will be considered for every transaction it will be helpful for bringing transparency in marketing system. As government have access to all database it can check merchants warehouse/ storage quantity, by which government will come to know different stocks possessed by merchants and this will help in preventing black marketing of food grains and try to avoid artificial inflation. 
Vol. 6, Issue 5, May 2017

\section{RELATED WORK}

Manav Singha, Kshitij Verma, Anupam Shukla introduced "Krishi Ville - Android based Solution for Indian Agriculture." In this paper authors proposed an android based mobile application Krishi Ville, This application will update different agriculture news, commodities and weather forecast updates. This paper focuses on rapid growth mobile telephony and introduction of new technologies in mobile information services which can play important role to overcome the existing information asymmetry. Use of mobile technology helps to bridge the gap between availability and delivery of agriculture inputs and infrastructure.[1]

L. Pradhan, B. B. Mohapatra, Fakir Mohan, (2015) proposed "E-agriculture: A Golden Opportunity for Indian farmers". This study explores the important role of Information Communication Technology in agricultural marketing. Paper focuses on improved record keeping related to agriculture using ICT for more detailed market strategies and cost analysis. Using ICT farmers can be connected with different facilities like rural banking, government schemes by providing farmers with unique identity card or e-passbook which is machine readable and have biometric access. ICT and E-agriculture will help in addressing many of challenges faced by Indian community and will help in uplifting the livehood of Indian farmers.[2]

Sindhu M R, AdityaPabshettiwar, Ketan.K.Ghumatkar, Pravin.H.Budhehalkar, Paresh.V(2012) proposed "E-Farming". This paper states that E-farming will serve as an efficient platform for Indian farmers to sell their product across country market with just basic knowledge of website. E-farming will help farmers to perform online agro-marketing leading to achieve good prices and increase their standard of living. E-agriculture website will also commodity wise, market wise updates to farmers in easy and interactive way.[3]

D.Vinoth1,K.Shanmugapriya, (2015) presented "E-Agro Crop Marketing for Farming Community". The prime intent of this paper is to design a website that will helps farmers to sell their agriculture products to other markets in different locations in country. It is a computerized approach for transparent and better marketing. E-Agro Crop Marketing would provide information to the farmers about current market rate of agro-products, their previous records like sale history and profits earned in a sale. This site will also help the farmers to know about the market information to keep them timely updated and to view agricultural schemes announced by Government.[4]

SumithaThankachan, Dr. S.Kirubakaran, (2014)proposed "E-Agriculture Information Management System". This paper concentrates on technological importance of information in agriculture sector for further decision making and finding markets current statistics. The paper highlights e-agriculture as a platform for supporting marketing of agriculture products. This paper carries statistical survey to check the awareness of farmers about e-commers and emarketing platform. Paper discuses strategies for improving productivity in agriculture and timely updates are provided to farmer in easy and personalized situation.[5]

GhodkeTushar D. DevdeNitin N proposed in the paper "E-Farming: an Innovative Approach for an Indian Farmer" a web based system which will provide easy interactive platform for different stakeholders like farmer, bank authority, government. Through this system bank authority will provide loan information and government can display different schemes, weather information for farmers, system will provide an effective communication within three entities and simple and reliable banking system for farmers.[6]

NileshDumbre presented "System for Agriculture Recommendation Using Data Mining" This Paper focuses on making use of different data mining techniques for betterment of agriculture by understanding soil and climate condition and with the help of different data mining algorithms system will suggest suitable crops for farmers land. So it will be easy for farmers to decide which crop to in his soil unpredictable condition. Data mining algorithms will help to answer different questions that cannot be addressed through simple query reporting technique.[7]

\section{PROPOSED METHODOLOGY}

The main aim of E-agriculture system is to provide easy interactive platform for communication and information exchange between farmer, merchant and government. All these three users will have their unique log in. All the system related transactions are done using this login ID will make easy to keep watch on overall processes between different entities. Farmers can add information about their crops and crops quantity on this basis they search merchants from nearest APMC markets. List of merchants will be displayed on screen with prices offered by merchants. From this list farmer can send selling request to highest price offering merchant and if merchant accept request transaction can be performed. All this transaction details will be recorded and will be available for all three stakeholders. In similar way 
merchant can also search for farmers from database with required crops and send request to them for buying purpose. Prices offered by different merchants to different agriculture product will be displayed to farmers as per there request. Government defined base prices of crops and timely weather updates will be displayed at home pages of both farmers and merchant. This will helpful to assure that farmer will get fair prices for his products. In proposed E-agriculture system government acts as an administrator. Government can find out different crops quantity at farmers and merchants records. Government will also able to see each and every transaction between farmers and merchants, this will helpful for bringing transparency in agriculture market. Along with this system will reduce the corruption, inconvenience and uneasiness of viewing market and will provide one touch access to descent and accurate market information.

\section{ALGORITHMS:}

\section{1] Knn algorithm:}

- $\quad \mathrm{Knn}$ is a k-nearest neighbors algorithm. In this system Knn algorithm is used to find out the nearest APMC market from farmers location. Knn algorithm is used in both farmer and merchant module. In Farmer module it finds nearest APMC markets and in Merchant module it is used to display farmers registered in nearest APMC. During registration users geographical co-ordinates longitude and latitude are stored in database, location co-ordinates of APMC market are also stored in another database table. Knn algorithm uses euclidean distance formula for computing distance between users location and APMC market. After this information from nearest APMC is displayed.

- $\quad$ Let $\mathrm{X}$ be the coordinate of users i.e farmers/merchants location such that $\mathrm{X}$ (Longitude, Latitude) and (M1,M2,M3.....Mn) and M (Longitude, Latitude). Knn algorithm calculates distance between users location i.e. X and every markets location. Such as Dist (X,M1), Dist (X,M2), . Dist (X,Mn).

After finding all distances these distance records are compared and arranged in ascending order and nearest market is displayed.

- $\quad$ Euclidean distance formula :

$$
\begin{aligned}
\mathrm{d}(\mathbf{p}, \mathbf{q})=\mathrm{d}(\mathbf{q}, \mathbf{p}) & =\sqrt{\left(q_{1}-p_{1}\right)^{2}+\left(q_{2}-p_{2}\right)^{2}+\cdots+\left(q_{n}-p_{n}\right)^{2}} \\
& =\sqrt{\sum_{i=1}^{n}\left(q_{i}-p_{i}\right)^{2}} .
\end{aligned}
$$

\section{2] Apriori algorithm:}

Apriori Algorithm is used for finding frequent item sets from database. This methods is for finding all frequent item sets efficiently. The apriori algorithm is at core of various algorithms for data mining problems. We have used this algorithm for finding lists of merchants buying the selected crops by farmer. And also for finding farmers having crops required by merchant.

When Farmer/Merchant wants to sell/buy crops then crop names will be selected by them.

Step 1:- This set of crop names is used as the input to the apriori algorithm.

Step 2:- Algorithm will check for the input set records in database.

Step 3:- If any record is found in database having all or any of the input record match then the entry that record is added to result array.

Step 4:- Again next records are searched from database for an of the match this records are entered in result array set.

Step 5:- Same procedure is followed throughout until complete database is scanned.

Step 6:- The result string now contain all the Farmers/ Merchants having crops similar to input string.

In this system we are interested to find all the farmers and merchants though they have single crop in their records. Hence to find these merchants/farmers we have defined threshold to apriori algorithm as one. This will make display the names of merchant, farmers with single crop entry.

\section{3] K-means algorithm:}

K-means algorithm is used for clustering purpose. K-means algorithm is used in government module. K-means algorithm is used for forming crop wise clusters of farmers and merchants. We are applying this methodology in government side so that by clustering data into separate cluster it will become easy for analysis purpose. 
Step 1) APMC market who's data is to be analysed is selected.

Step 2) Data is to be clustered from selected APMC according to different crops available in that market.

Step 3) K-means algorithm generates k clusters from database. Where $\mathrm{k}$ is equal to the number of crops in database. i.e. if there are $\mathrm{n}$ crops in database then $\mathrm{n}$ clusters will be formed, such that each cluster contains data related to one crop.

Step 4) For K-means algorithm $\mathrm{k}<\mathrm{d}$, Where $\mathrm{k}=$ number of clusters to be formed and $\mathrm{d}=$ number of data records.

\section{4] MD-5 algorithm:}

In E-agriculture system MD5 algorithm is used for user's data security and integrity purpose, this algorithm encrypts the $\log$ in details of farmers and merchants in database.

MD 5 algorithm is used for data security purpose. MD 5 is message digest algorithm it is a cryptographic algorithm that takes an input of arbitrary length and produces a message digest that is 128 bits long.

Step 1) Append padding bits:-The input message is "padded" (extended) so that its length (in bits) equals to 448 mod 512. Padding is always performed. Padding is performed as follows: a single " 1 " bit is appended to the message, and then "0" bits are appended so that the length in bits of the padded message becomes congruent to $448 \bmod 512$.

Step 2) Append length A 64-bit representation of the length of the message is appended to the result of step1. If the length of the message is greater than 2 raise to 64, only the low-order 64 bits will be used.

Step 3) Initialize MD buffer A four-word buffer (A, B, C, D) is used to compute the message digest. Each of A, $\mathrm{B}, \mathrm{C}, \mathrm{D}$ is a 32-bit register.

Step4) Process message in 16-word blocks: Four functions will be defined such that each function takes an input of three 32-bit words and produces a 32-bit word output.

\section{SYSTEM ARCHITECTURE:}

Proposed system of E-agriculture system using data mining techniques is deployed using java technology on apache web server. System uses eclipse as development IDE. System uses MySql database allowing user to perform queries directly onto any schema that user choose.

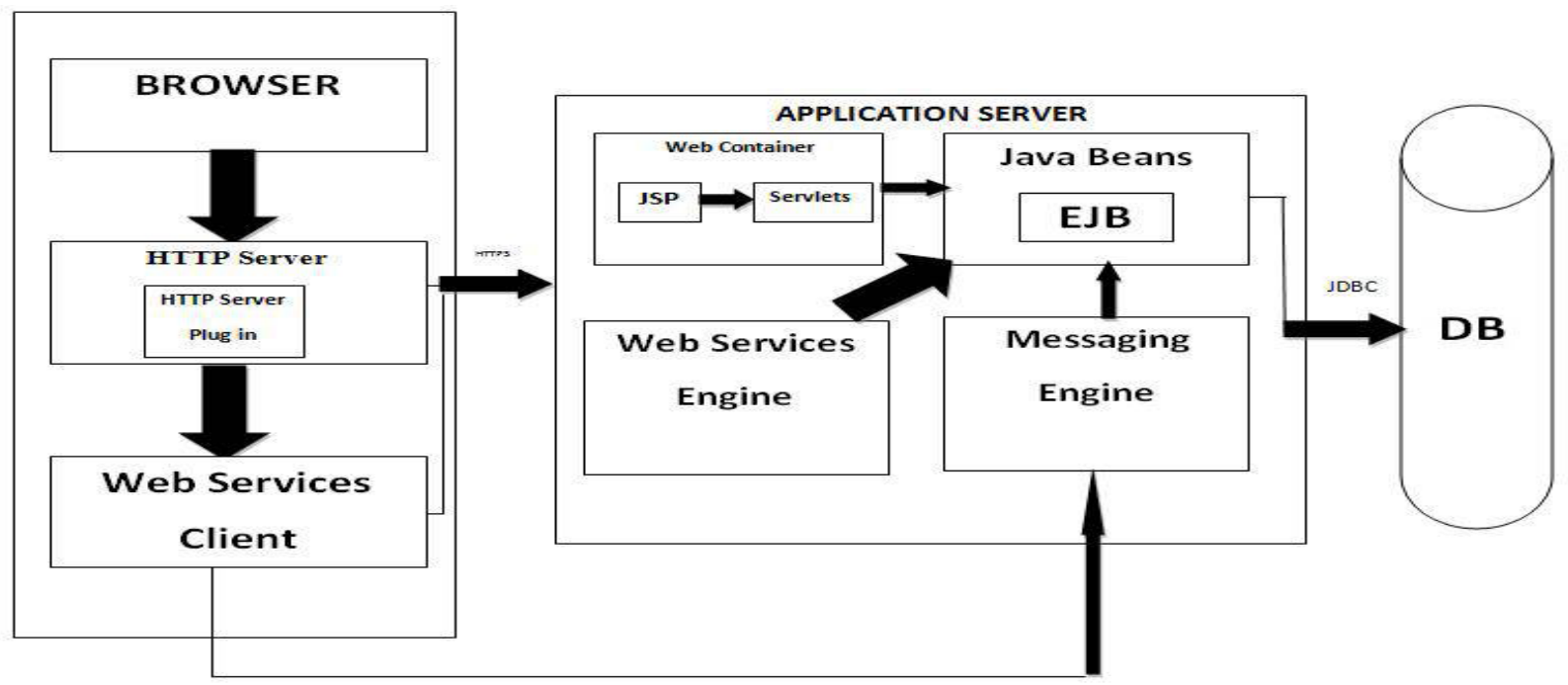

Fig 1. Proposed system architecture

\section{RESULTS AND DISCUSSIONS}

E-agriculture system works efficiently over already existing manually operated market system. E-agriculture is providing user friendly interface and access to different information with time efficiency. Using this system farmer's will have access to accurate and updated market information with just one click. System will provide up to date transactions details government which will helpful for analysing market status and deciding further policies and schemes regarding agriculture sector. Proper management of agriculture related data using information communication technology and processing of this data using data mining techniques will provide efficient analysis and study environment for available data. 


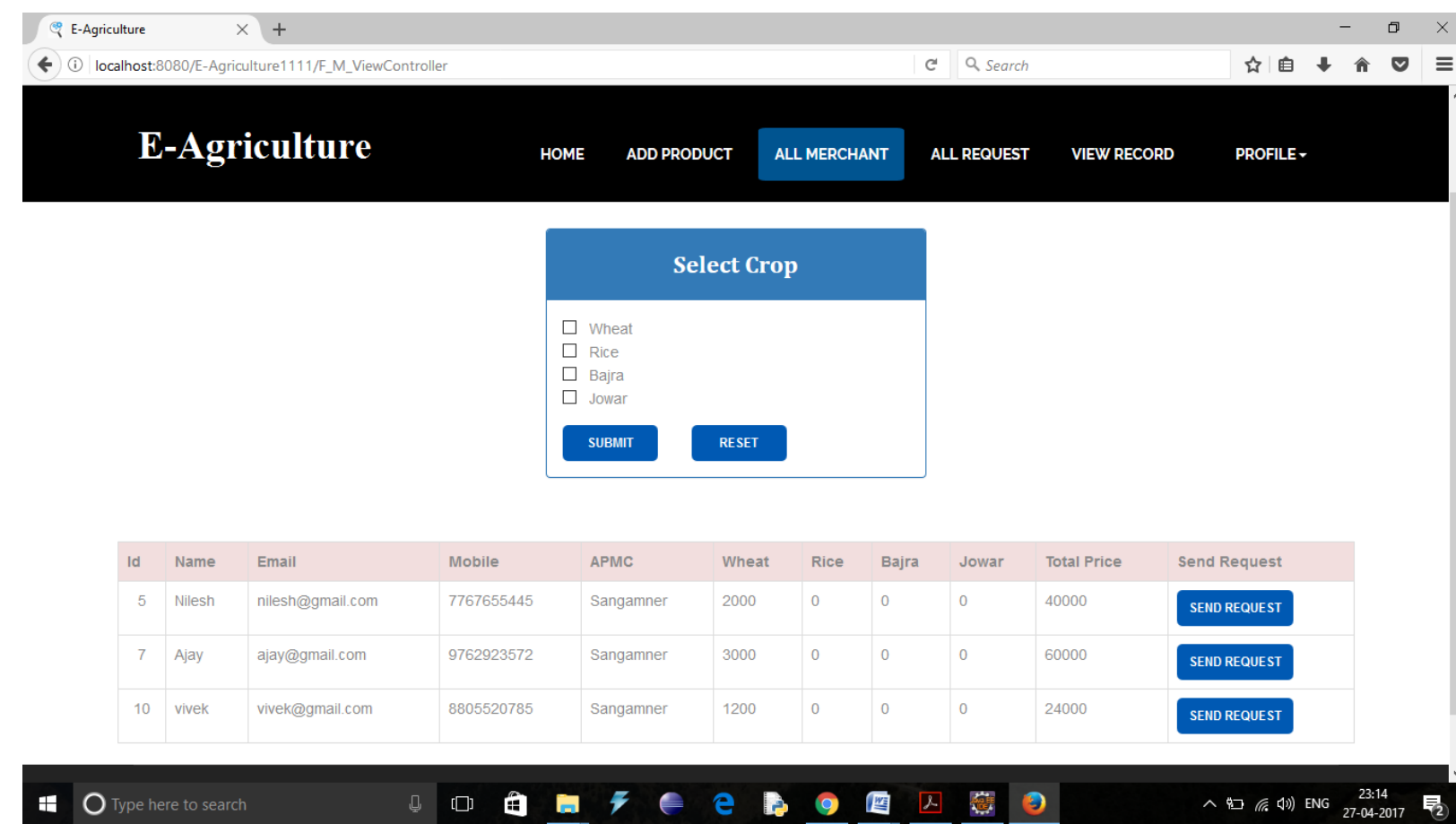

Fig-2: Farmers- Find Merchant (screenshot).

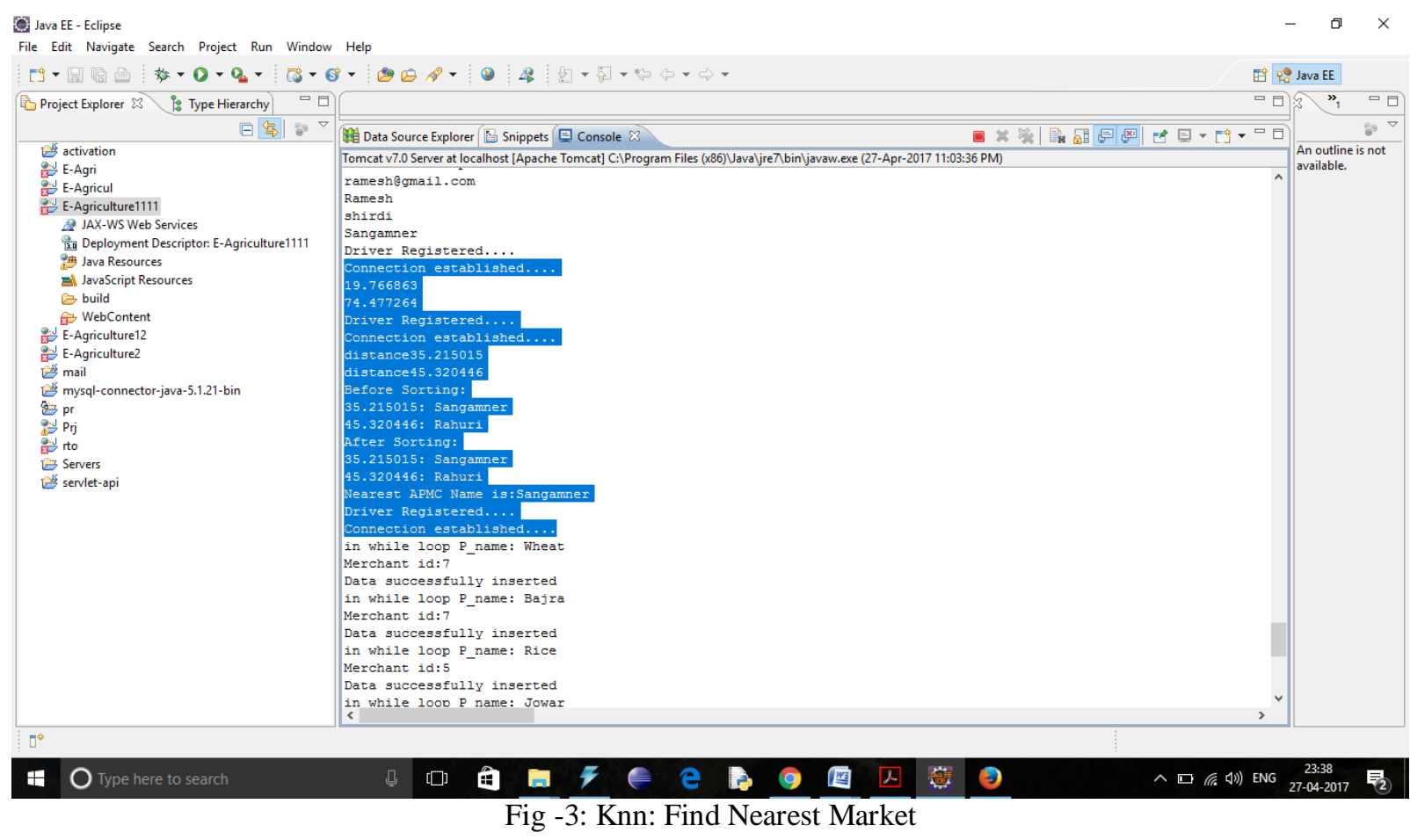

\section{CONCLUSION AND FUTURE WORK}

E-Agriculture platform will serve as an easy and efficient way to farmers their marketing crops and sell them across different market through computerized system. E-agriculture will establish direct communication between farmer traders this will avoid intermediate commission agents and farmer will not be levies with extra unnecessary taxes and charges, this will help farmer to gain fair and worthful price for their product. In future work E-agriculture system can also be connected with different agencies like bank, fertilizers sellers, agriculture experts, veterinaries etc. EAgriculture system will play important role in bringing farmers to digitalization's main stream and will prepare them to compete with globalised market. 


\section{REFERENCES}

[1] Manav Singhal1, Kshitij Verma2, Anupam Shukla3 ABV-Indian Institute of Information Technology and Management, Gwalior, India "Krishi Ville - Android based Solution for Indian Agriculture", 2011 Fifth IEEE International Conference on Advanced Telecommunication Systems and Networks (ANTS)

[2] 1. pradhan, b. b. mohapatra faculty of economics, fakir mohan, "e-agriculture: a golden opportunity for indian farmers",756019, orissa, in-dia. issn (print): 23195479, volume-4, issue1, 2015.

[3] Sindhu M R, AdityaPabshettiwar, Ketan.K.Ghumatkar,Pravin.H.Budhehalkar, Paresh.V., "E-Farming”. International Journal of Computer Science and Information Technologies, Vol. 3 (2), 2012, 3479-3482.

[4] D.Vinoth1, K.Nisharth2 and K .Shanmugapriya, "E-Agro Crop Marketing for Farming Community", International Journal in Foundations of Computer Science Technology (IJFCST), Vol.5, No.2, March 2015.

[5] SumithaThankachan, Dr. S.Kirubakaran, "E-Agriculture Information Management System". International Journal of Computer Science and Mobile Computing, Vol.3 Issue.5, May-2014, pg. 599-607.

[6] E-Farming: an Innovative Approach for an Indian FarmerGhodkeTusharD,DevdeNitinN,Agwan Sagar C. Kudal Yogesh ,Prof. Kumbharde M. V Department of Computer Engineering SNDCOE \& RC, Yeola, India

[7] NileshDumbre, OmkarChikane, Gitesh More, "System for Agriculture Recommendation Using Data Mining". Department of computer Engineering,.SavitribaiPhule Pune Univerity, Maharashtra, India.Research Paper Engineering E-ISSN: 2454-9916, Volume: 1, Issue: 5, Dec 2015.

[8] Indian Journal Of Agricultural Economics, 52(1)

[9] N.L. Agarwal (2004), agricultural marketing in india, 4th edition, Oxford and ibh, New Delhi.

[10] Website: Maharashtra state agriculture marketing board (masamb) https:// www.msamb.com/apmc/default.htm

[11] Website: /agmarknet.gov.in

[12] Yubo Jia, Guanghu Xia, Hongdan Fan, Qian Zhang, Xu Li School of Information Science and Technology, An Improved Apriori Algorithm Based on Association Analysis, 2012 Third International Conference on Networking and Distributed Computing

[13] Sanjay Chaudharyl, Minai Bhise2, Asim Banerjee2 Institute of Engineering and Technology, Ahmedabad University, Ahmedabad, India "Agro Advisory System for Cotton Crop", AGRINETS Workshop, COMSNETS 2015

[14] H A. Ghogare, Priyanka m. Monga, Ram Meghe, "E-agriculture Introduction and Figuration of its application". International journal of advanced research in computer science and soft-ware engineering, volume 5, issue 1, january 2015. 